\title{
Psychosocial Rehabilitation Through Intervention by Second Language Acquisition in Older Adults
}

\author{
Marcel Pikhart ${ }^{1}$ (D) Blanka Klimova ${ }^{1} \cdot$ Anna Cierniak-Emerych $^{2} \cdot$ Szymon Dziuba $^{2}$
}

Accepted: 30 July 2021 / Published online: 11 August 2021

(c) The Author(s) 2021

\begin{abstract}
The paper deals with a possibility of foreign language learning (FLL) intervention in older adults as a psychosocial rehabilitation method to improve the quality of life (QoL) in this age segment, i.e. the people who are over 55 years. FLL has been researched as a successful tool to maintain or even enhance cognitive functions in older age along with other intentional activities, such as engagement in any physical activity. FLL cannot dramatically improve memory and cognitive deterioration of older adults, however, it can improve QoL by increasing subjective happiness that is connected to improved wellbeing. The research was conducted in two groups of seniors who are engaged in FLL, specifically in the Czech Republic and Poland. The major premise of the research was based on the positive psychology concept, i.e., the subjective happiness leads to improved levels of QoL. Both groups consisted of about a hundred respondents whose opinions were researched by an online questionnaire. The major focus of this questionnaire was to evaluate the level of subjective happiness and then compare the results obtained from the respondents from these two geographically different regions. The findings clearly showed that those who had engaged in FLL had reached high levels of subjective happiness, therefore, their subjective wellbeing could be improved. These results might be important for psychosocial rehabilitation practices because they can create a framework for further non-pharmacological intervention to maintain healthy aging. FLL can thus be a very efficient tool for any psychosocial rehabilitation in older healthy adults who do not suffer from any cognitive pathological development but who are just experiencing negative side effects of natural aging process. The research into this topic is very scarce, and therefore, this paper could be an inspiration for further and larger-scale research.
\end{abstract}

Keywords Foreign language learning · Psycholinguistics $\cdot$ FLL $\cdot$ L2 acquisition · Seniors · Wellbeing $\cdot$ Aging $\cdot$ Cognitive decline $\cdot$ Successful aging $\cdot$ Healthy aging

Marcel Pikhart

marcel.pikhart@uhk.cz

Extended author information available on the last page of the article 


\section{Introduction}

The research into various aspects of foreign language learning (FLL) is ample, however, there is a significant impact of FLL on maintaining or even enhancing cognitive parameters in older adults as well (Klimova, 2018; Klimova et al., 2016; Phenniger et al., 2018; Pikhart \& Klimova, 2020; Valis et al., 2019). The natural aging process is connected to many psychological and mental aspects and one of them is the process of cognitive decline, well documented by numerous research (Murman, 2015; Salthouse, 2010). It is an inevitable process connected to aging, however, there are various activities that could have a potential to slow down this natural process, such as music, natural environment, nutrition, physical activity, mental activity, arts, or political and civic engagement (Cann, 2017; Elzen et al., 2019; Erickson et al., 2009; Gil-Lacruz et al., 2020; Klimova et al., 2020; MacKean et al., 2011; Mathis et al., 2016; Socci et al., 2020; Serrat et al. 2019, Serrat et al., 2015; Wilson et al., 2006). These non-pharmacological intervention activities work very well in various psychological perspectives and it is very clear that they improve objective physical and mental status, and consequently, also subjective wellbeing of the participants of these activities.

Quality of life (QoL) is connected to objective parameters, such as healthy lifestyle, physical activity, or social contacts, but also to subjective parameters, and these are very much associated with subjective-therefore, difficult to measure-feelings of happiness. The basic premise of this paper is that QoL is significantly influenced by subjective feelings of happiness. If it is so, how much FLL can improve these subjective feelings of happiness and thus lead to improved subjective wellbeing and hence QoL? There is a clear correlation between subjective feelings of satisfaction and happiness. Moreover, happiness correlates with improved QoL.

FLL has not much been associated with happiness and wellbeing but rather on the contrary. Learning psychology maintains that schooling and education can lead to the systematic oppression of creativity and in some cases, even to depression (Zhang et al., 2020). However, recent research into FLL and psycholinguistics has shown (Pikhart \& Klimova, 2020) that in older generation FLL can have a very different impact on the personality through improved subjective feelings of satisfaction. In younger adults, the research results indicate that despite their relatively good study results and learning outcomes in FLL or second language (L2) acquisition, they do not reach very high levels in their subjective satisfaction and feelings of wellbeing connected to their FLL. These younger learners see their FLL as a pragmatic activity leading to certain results, necessary for their work and future prospects of travelling and earning money. They do not experience any elevated levels of happiness arising from their FLL per se. The learning activity is a must for them because it brings monetary benefits and a future competitive advantage (Kormos \& Csizer, 2008). On the contrary, in older adults-despite their slightly worse objective learning results in their L2 acquisition-they usually express their inner subjective satisfaction with their FLL regardless of their not very motivating objective outcomes. This goes in opposition with traditional learning psychology theory, i.e., the good learning results are a motivator and the poor learning results are a demotivator. Counterintuitively, in a generational comparison, it does not work so and this assertion is not applicable.

Moreover, FLL can be used as a tool for psychosocial rehabilitation because the learning process always works as a cognitively-mental tool and FLL is usually a social activity, at least in the case of class learning. Moreover, FLL can also be one of the non-pharmacological tools to slow down the onset of serious neurodegenerative diseases, as research 
has recently confirmed (Antoniou et al., 2017; Bubbico et al., 2019; Klimova et al., 2016). Psychosocial rehabilitation through FLL can, therefore, have a potential to be a relatively useful and cheap method to enhance subjective wellbeing of participants through the intervention by cognitive training, and societies can benefit from this by saving costs on pharmacological interventions in serious cognitive illnesses whose onset can be thus delayed (Ware et al., 2017; Wong et al., 2019).

The research question was as follows: How much will the level of subjective wellbeing be influenced by the participation in FLL in older adults? If the level of wellbeing reaches very high levels, it is possible to come to a conclusion that FLL improves significantly the wellbeing levels and therefore can be very efficient tool for psychosocial rehabilitation in older age.

\section{Methodology}

The research sample included two groups of older individuals at the age of $55+$ years from two neighboring Central European countries, specifically, Poland and the Czech Republic. The Czech sample consisted of 105 participants and the Polish sample comprised 100 participants. All were either attendees of the University of the Third Age (U3A) or studied a foreign language privately. The respondents did not suffer from any serious cognitive or mental impairments, such as dementia or Alzheimer's disease.

The participants (randomly selected by e-mail contacts) were asked to fill in an online questionnaire via Google Forms. The questionnaire included 20 statements concerning elderly people's attitude to FLL from the viewpoint of positive psychology, as well as four questions on their demographic data. The questionnaire in a slightly modified version following a standardized questionnaire designed by Woll \&Wei (2019). The participants provided their responses on the 6-point Likert scale (strongly agree, agree, agree a little, disagree a little, disagree, and strongly disagree). The collection of data was conducted between April 2020 and June 2020.

The research complies with the Helsinki declaration because all participants were informed about the purpose of the study, and about the possibility of withdrawing from participation in the research at any time, as well as giving informed and voluntary consent to participate in this research. The intervention by FLL, i.e. the participation in the FLL class, had been approved by the written consent of all participants before the course started. All the regulations demanded by the EU regulation GDPR were followed, i.e. no personal data about the participants was collected or stored. The only identification of the questionnaire was the data stamp of the questionnaire that does not contain any other information but the date and time of the data collection. No IP addresses were collected either. This research was approved by the Ethics Committee of the University of Hradec Kralove (no. 2/2021).

The paper used the methods of descriptive statistics and parametric and non-parametric significance tests of differences between independent groups as they could easily reveal the answer to the research question and clearly indicate the relevance of FLL and its impact on the subjective feelings of happiness. Furthermore, reliability coefficients were calculated for the scales created, based on the modified Q-Sort method for subject-related data sorting. In addition, multidimensional regression analyses were performed to determine which demographic variables would affect the assessment of language learning at individual 
scales among people of both nationalities. The calculations were performed using the PQ Stat software, ver. 18.0. The statistical significance was set at $p=0.05$.

\section{Results}

The research tool was a list of twenty statements covering various advantages and disadvantages of FLL in terms of mental wellbeing. The research result analysis uses selected statements relating to the advantages of language learning. The participants responded on a scale of 1 to 6 points (6-I absolutely agree, 5-I agree, 4-I agree partially, to 1-I absolutely disagree). The answers were grouped into three categories (I agree, I disagree, I am not sure) for legibility of interpretation (Table 1). Of all respondents, 94\% provided complete answers that were used in the survey (100\% PL, $88 \% \mathrm{CZ}$ ).

Table 1 contains average values and standard deviations for individual items (statements) concerning the positive effects of language learning. The vast majority of respondents from both countries agreed with the statements. Differences in mean assessments between the Czech and Polish seniors are therefore largely due to more frequent choices of more unequivocal positive replies by the Polish respondents (I absolutely agree, I agree) compared to the Czech respondents (e.g. statements 1, 9, 11, 13). Three statements with the greatest differences between countries in the frequency of agreement and disagreement were distinguished. These are the statements number 3, 4 and 10 in Table 1, they are also highlighted in bold letters.

Individual statements were categorized into four thematic groups (scales), based on their content, i.e. intellect, travelling and future, positive emotions, and purpose and motivation. Table 2 contains sets of statements on each scale and reliability coefficients. The quality of scales measured by reliability was good or very good in the Czech study (Cronbach's $\alpha$ coefficient from 0.78 to 0.93 ) and slightly lower in the Polish study (Cronbach's $\alpha$ coefficient from 0.72 to 0.91 ). The scale of Positive emotions was the most consistent, whereas the least consistent was the scale of Travelling and future. The statement 5 ("Learning a new language improves my creativity") was excluded during analysis as it is inconsistent with other statements (taking it into account on the Intellect scale significantly reduced the $\alpha$ coefficient for each country).

The Poles assessed the positive effects of FLL significantly higher than the Czechs in every aspect: intellectual $(p<0.001)$, travelling and future $(p<0.01)$, positive emotions $(p<0.01)$ and life purpose and motivation $(p<0.01)$, see Table 3.

The statistical analysis of the mean assessments of the effects of FLL on mental wellbeing considered the following demographic variables: age, gender, level of education, number of languages learnt at the time of the survey and the currently learnt language.

Age: Comparison of peers from Poland and the Czech Republic revealed that wherever significant differences had occurred, the mean higher assessments had been always given by the Polish respondents (Table 4).

Gender: The analysis of the differences in the perceived effects of FLL on wellbeing between the genders (male and female) revealed the following statistically significant relationships: The Polish females evaluated the positive effects of FLL significantly higher than the Czech females in every aspect: intellectual $(p<0.001)$, travelling and future $(p<0.001)$, positive emotions $(p<0.001)$ and life purpose and motivation $(p<0.001)$. On the contrary, there were no statistically significant differences in the assessment of individual dimensions of the quality of life between the males from both countries (Table 5). 


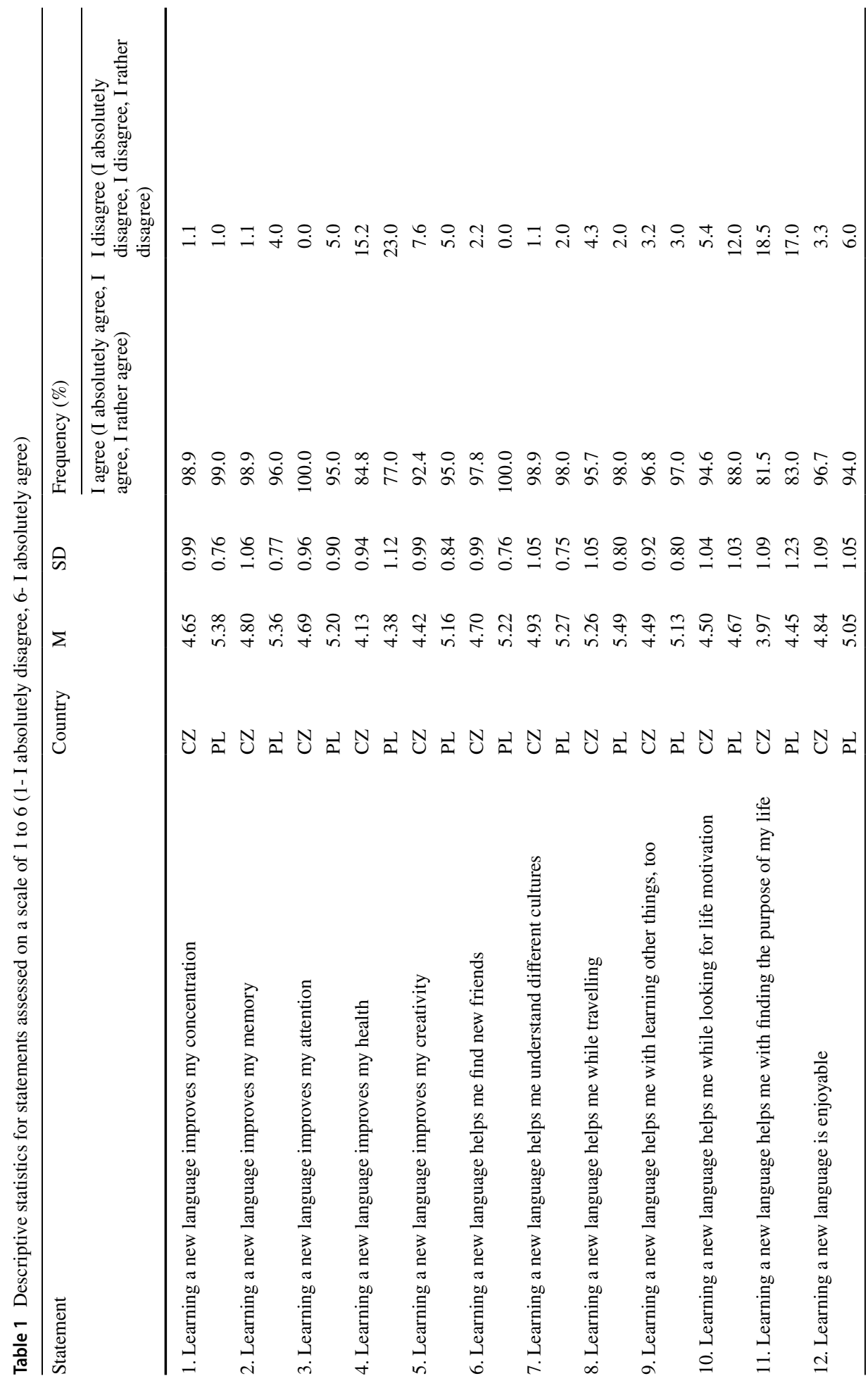




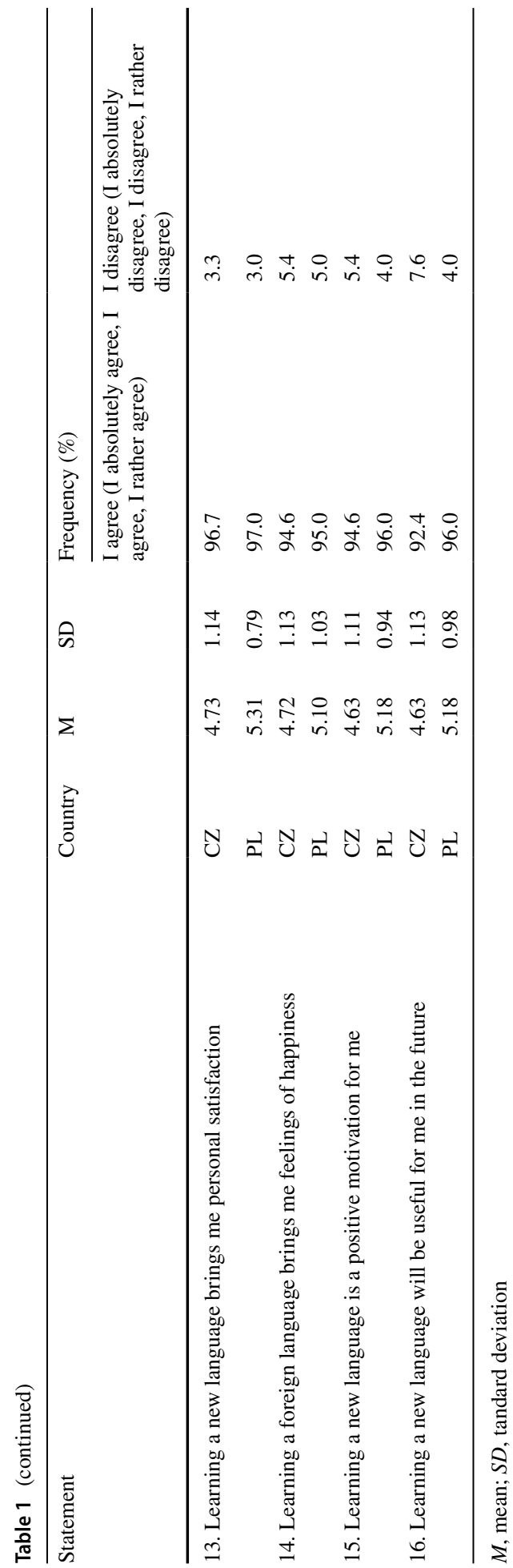


Table 2 Statements in individual scales and reliability of the scales

\begin{tabular}{|c|c|c|c|}
\hline \multirow[t]{2}{*}{ Scale } & \multirow[t]{2}{*}{ Items } & \multicolumn{2}{|c|}{$\begin{array}{l}\text { Scale } \\
\text { reliability } \\
\text { (Cron- } \\
\text { bach's } \alpha)\end{array}$} \\
\hline & & $\mathrm{CZ}$ & PL \\
\hline Intellect & $\begin{array}{l}\text { 1. Learning a new language improves my concentration } \\
\text { 2. Learning a new language improves my memory } \\
\text { 3. Learning a new language improves my attention } \\
\text { 9. Learning a new language helps me with learning other things, too }\end{array}$ & 0.86 & 0.85 \\
\hline Travelling and future & $\begin{array}{l}\text { 8. Learning a new language helps me while travelling } \\
\text { 7. Learning a new language helps me understand different cultures } \\
\text { 20. Learning a new language will be useful for me in the future }\end{array}$ & 0.78 & 0.72 \\
\hline Positive emotions & $\begin{array}{l}\text { 12. Learning a new language is enjoyable } \\
\text { 13. Learning a new language brings me personal satisfaction } \\
\text { 14. Learning a foreign language brings me feelings of happiness }\end{array}$ & 0.93 & 0.91 \\
\hline Purpose and motivation & $\begin{array}{l}\text { 10. Learning a new language helps me while looking for life motiva- } \\
\text { tion } \\
\text { 11. Learning a new language helps me with finding the purpose of } \\
\text { my life } \\
\text { 19. Learning a new language is a positive motivation for me }\end{array}$ & 0.81 & 0.72 \\
\hline
\end{tabular}

Table 3 Mean assessments of the Czechs and Poles on the scales of the effects of language learning and the significance of differences between the groups

\begin{tabular}{lllllll}
\hline Scale & \multicolumn{2}{l}{$\mathrm{CZ}(n=92)$} & & \multicolumn{2}{l}{$\mathrm{PL}(n=100)$} & Significance of differences \\
\cline { 2 - 3 } & $\mathrm{M}$ & $\mathrm{SD}$ & & $\mathrm{M}$ & $\mathrm{SD}$ & \\
\hline Intellect & 4.7 & 0.8 & & 5.3 & 0.7 & $U=2708, p<0.001^{* *}$ \\
Travelling and future & 4.9 & 0.9 & & 5.3 & 5.3 & $U=3653,5 p=0.006^{*}$ \\
Positive emotions & 4.8 & 1.0 & & 5.1 & 0.9 & $t(190)=-2.82, p=0.005^{*}$ \\
Purpose and motivation & 4.4 & 0.9 & & 4.8 & 0.9 & $t(190)=-3.11, p=0.002^{*}$ \\
\hline
\end{tabular}

*statistically significant difference at $p<0.01 * *$ statistically significant difference at $p<0.01$

Place of residence: The comparative analysis showed that there were no significant differences in the assessment of positive effects of FLL between the inhabitants of the cities and the inhabitants of rural areas from both countries (Table 6).

Education: In the group of people without higher education (in the Czech Republic, these were people with secondary education, whereas in Poland-people with primary and vocational education), the Czechs assessed the increase in positive emotions caused by learning a foreign language higher than the Poles. In other assessments, the inhabitants of Poland and the Czech Republic with a comparable level of education did not differ from each other (Table 7).

Number of languages: At the time of the survey, there were $67.4 \%$ Czech learners and $70.0 \%$ Polish learners of one foreign language, $17.4 \%$ Czechs and $23.0 \%$ Poles learning two languages, and $15.2 \%$ of Czechs and $7.0 \%$ of Poles learning three languages. There were no differences in the assessment of the positive effects of language learning between the groups of the Czechs and Poles learning the same number of languages (Table 8). 


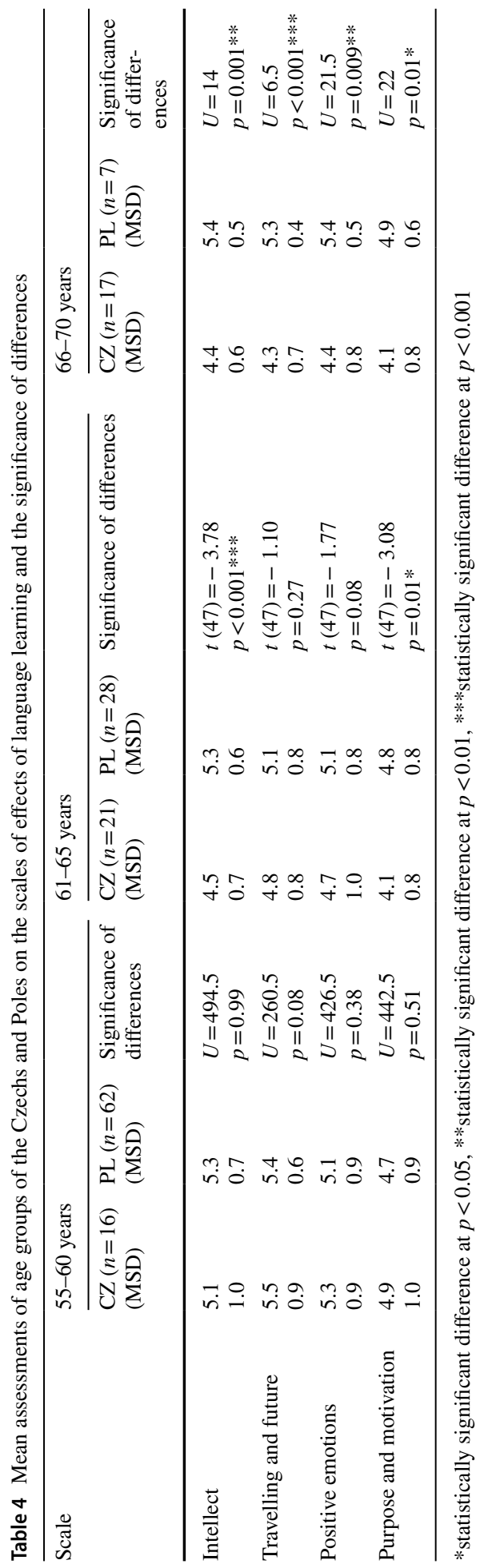




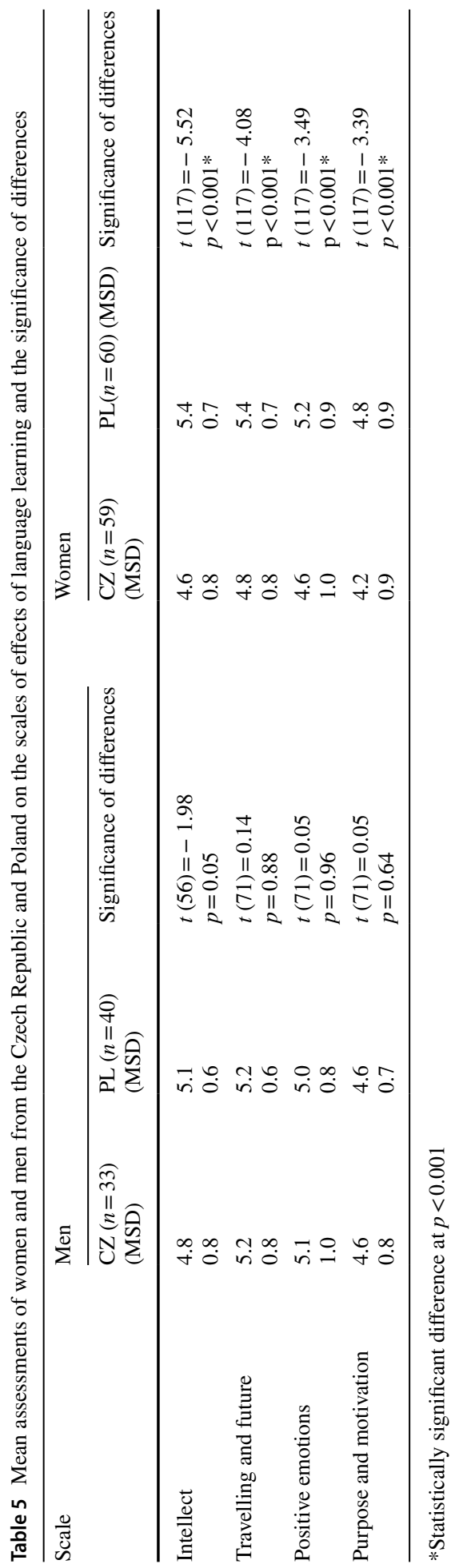


Table 6 Mean assessments of people living in rural areas and cities from the Czech Republic and Poland on the scales of the effects of language learning and the significance of differences

\begin{tabular}{|c|c|c|c|c|c|c|}
\hline \multirow[t]{2}{*}{ Subscale } & \multicolumn{3}{|c|}{ Inhabitants of cities } & \multicolumn{3}{|c|}{ Inhabitants of rural areas } \\
\hline & $\begin{array}{l}\mathrm{CZ} \\
(n=63) \\
(\mathrm{MSD})\end{array}$ & $\begin{array}{l}\mathrm{PL} \\
(n=84) \\
(\mathrm{MSD})\end{array}$ & $\begin{array}{l}\text { Significance } \\
\text { of differences }\end{array}$ & $\begin{array}{l}\mathrm{CZ} \\
(n=29) \\
(\mathrm{MSD})\end{array}$ & $\begin{array}{l}\text { PL } \\
(n=16) \\
\text { (MSD) }\end{array}$ & $\begin{array}{l}\text { Significance } \\
\text { of differ- } \\
\text { ences }\end{array}$ \\
\hline Intellect & $\begin{array}{l}5.1 \\
0.8\end{array}$ & $\begin{array}{l}4.8 \\
0.8\end{array}$ & $\begin{array}{l}U=2233 \\
p=0.10\end{array}$ & $\begin{array}{l}5.0 \\
0.8\end{array}$ & $\begin{array}{l}5.2 \\
0.9\end{array}$ & $\begin{array}{l}U=191 \\
p=0.33\end{array}$ \\
\hline Travelling and future & $\begin{array}{l}5.2 \\
0.7\end{array}$ & $\begin{array}{l}5.1 \\
0.8\end{array}$ & $\begin{array}{l}U=2596 \\
p=0.84\end{array}$ & $\begin{array}{l}5.1 \\
1.0\end{array}$ & $\begin{array}{l}5.4 \\
0.8\end{array}$ & $\begin{array}{l}U=177.5 \\
p=0.18\end{array}$ \\
\hline Positive emotions & $\begin{array}{l}5.0 \\
1.0\end{array}$ & $\begin{array}{l}4.8 \\
1.0\end{array}$ & $\begin{array}{l}U=2408.5 \\
p=0.34\end{array}$ & $\begin{array}{l}5.0 \\
0.9\end{array}$ & $\begin{array}{l}5.3 \\
0.9\end{array}$ & $\begin{array}{l}U=177.5 \\
p=0.17\end{array}$ \\
\hline Purpose and motivation & $\begin{array}{l}4.5 \\
0.9\end{array}$ & $\begin{array}{l}4.5 \\
0.9\end{array}$ & $\begin{array}{l}U=2597.5 \\
p=0.85\end{array}$ & $\begin{array}{l}4.7 \\
0.9\end{array}$ & $\begin{array}{l}4.9 \\
0.7\end{array}$ & $\begin{array}{l}U=192 \\
p=0.34\end{array}$ \\
\hline
\end{tabular}

Table 7 Mean assessments in groups of education of the Czechs and Poles on the scales of effects of language learning and significance of differences

\begin{tabular}{|c|c|c|c|c|c|c|}
\hline \multirow[t]{2}{*}{ Subscale } & \multicolumn{3}{|c|}{ Secondary and lower education } & \multicolumn{3}{|c|}{ Higher education } \\
\hline & $\begin{array}{l}\mathrm{CZ} \\
(n=38) \\
(\mathrm{MSD})\end{array}$ & $\begin{array}{l}\mathrm{PL}(n=8) \\
(\mathrm{MSD})\end{array}$ & $\begin{array}{l}\text { Significance } \\
\text { of differences }\end{array}$ & $\begin{array}{l}\mathrm{CZ} \\
(n=54) \\
(\mathrm{MSD})\end{array}$ & $\begin{array}{l}\mathrm{PL} \\
(n=92) \\
(\mathrm{MSD})\end{array}$ & $\begin{array}{l}\text { Significance } \\
\text { of differ- } \\
\text { ences }\end{array}$ \\
\hline Intellect & $\begin{array}{l}5.1 \\
0.7\end{array}$ & $\begin{array}{l}4.7 \\
0.8\end{array}$ & $\begin{array}{l}U=108 \\
p=0.20\end{array}$ & $\begin{array}{l}5.0 \\
0.8\end{array}$ & $\begin{array}{l}4.9 \\
0.8\end{array}$ & $\begin{array}{l}U=2352.5 \\
p=0.59\end{array}$ \\
\hline Travelling and future & $\begin{array}{l}5.2 \\
0.6\end{array}$ & $\begin{array}{l}5.1 \\
0.8\end{array}$ & $\begin{array}{l}U=136 \\
p=0.65\end{array}$ & $\begin{array}{l}5.1 \\
0.8\end{array}$ & $\begin{array}{l}5.1 \\
0.8\end{array}$ & $\begin{array}{l}U=2336 \\
p=0.54\end{array}$ \\
\hline Positive emotions & $\begin{array}{l}5.1 \\
0.8\end{array}$ & $\begin{array}{l}4.1 \\
1.5\end{array}$ & $\begin{array}{l}U=82.5 \\
p=0.04^{*}\end{array}$ & $\begin{array}{l}4.9 \\
1.0\end{array}$ & $\begin{array}{l}5.0 \\
0.9\end{array}$ & $\begin{array}{l}U=2391.5 \\
p=0.70\end{array}$ \\
\hline Purpose and motivation & $\begin{array}{l}4.7 \\
0.8\end{array}$ & $\begin{array}{l}4.4 \\
1.4\end{array}$ & $\begin{array}{l}U=139 \\
p=0.72\end{array}$ & $\begin{array}{l}4.5 \\
0.9\end{array}$ & $\begin{array}{l}4.6 \\
0.9\end{array}$ & $\begin{array}{l}U=2240 \\
p=0.32\end{array}$ \\
\hline
\end{tabular}

*Statistically significant difference at $\mathrm{p}<0.05$

In order to identify the determinants of the assessment of different aspects of language learning, four independent logistic regression analyses were performed (for the scales of Intellect, Travelling and future, Positive emotions, Purpose and motivation) for each nationality. In each of these analyses, diverse demographic variables were used as predictors in the model. The basic models for each scale included all demographic variables from the survey: gender, age, level of education, place of residence, number of languages the respondent learnt at the time of the survey.

\section{Intellect Scale}

Czechs: In the model for the Intellect scale, the results show that an important predictor of the assessment of the effect of language learning on intellect is the number of languages learnt $(\beta=0.27, t=2.53, p=0.01)$. The significant model is as follows: $\mathrm{F}(3.90)=6.40$, $p=0.01$, and explains $6.6 \%$ of the variance (corrected $R^{2}=0.056$ ). The results mean that 


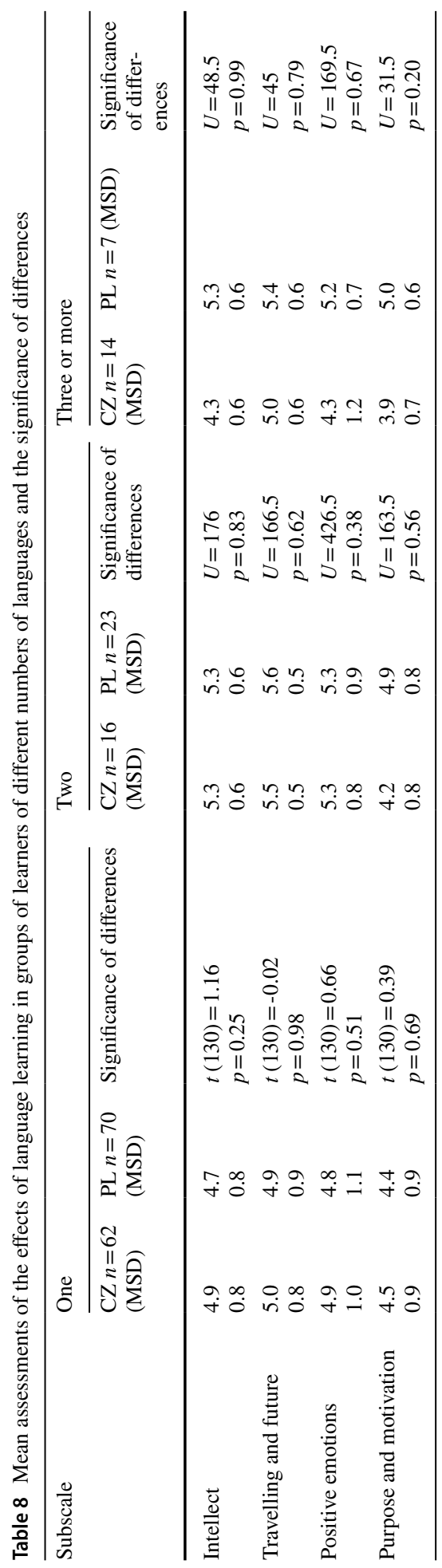


individuals who learn more languages will be more likely to see positive effects of language learning in the area of intellect.

Poles: In the model for the Intellect scale, the results showed that an important predictor of the assessment of the effect of language learning on intellect are gender $(\beta=-0.42$, $t=-2.52, p=0.01)$ and the number of languages $(\beta=0.38, t=3.08, p=0.003)$. Gender explains $6.1 \%$ of the variance (corrected $R^{2}=0.051$ ), whereas the number of languages explains $8.8 \%$ of the variance (corrected $R^{2}=0.078$ ). The results obtained mean that being a woman and the greater number of languages learnt increase the assessment of the positive effects of FLL in terms of intellectual abilities.

\section{Scale of Travelling and future}

Czechs: In the model for the scale of Travelling and future, the results show that an important predictor of the assessment of the effect of FLL on travelling and better future is the number of languages learnt $(\beta=0.28, t=2.69, p=0.008)$. The significant model is as follows: $\mathrm{F}(3.90)=7.22, p=0.01$ and explains $7.4 \%$ of the variance (corrected $\left.R^{2}=0.064\right)$. The results mean that individuals who learn more languages will be more likely to see positive effects of language learning in the area of travelling and future.

Poles: In the model for the scale of Travelling and future, the results show that an important predictor of the assessment of the effect of language learning on travelling and better future is the number of languages learnt $(\beta=0.32, t=2.52, p=0.01)$. The significant model is as follows: $\mathrm{F}(3.98)=6.37, p=0.01$ and explains $6.1 \%$ of the variance (corrected $R^{2}=0.051$ ). The results mean that individuals who learn more languages will be more likely to see positive effects of language learning in the area of travelling and future.

\section{Scale of Positive Emotions}

Czechs: In the model for the scale of positive emotions, none of the predictors was statistically significant.

Poles: In the model for the scale of positive emotions, the results showed that an important predictor of the assessment of the effect of language learning on positive emotions are gender $(\beta=-0.48, t=-2.33, p=0.02)$ level of education $(\beta=0.87, t=-2.33$, $p=0.02)$, and the number of languages $(\beta=0.34, t=2.15, p=0.03)$. Gender explains $5.2 \%$ of the variance (corrected $R^{2}=0.043$ ), level of education explains $4 \%$ of the variance (corrected $R^{2}=0.054$ ), and the number of languages explains $3 \%$ of the variance (corrected $R^{2}=0.045$ ). The results obtained mean that being a woman, having a higher level of education, and the greater number of languages learnt increased the assessment of the positive effects of language learning on the scale of positive emotions.

\section{Scale of Purpose and Motivation}

Czechs: In the model for the scale of purpose and motivation, none of the predictors was statistically significant.

Poles: In the model for the scale of purpose and motivation, the results show that an important predictor of the assessment of the effect of language learning on purpose and motivation is the number of languages learnt $(\beta=0.36, t=2.54, p=0.01)$. The significant model is as follows: $\mathrm{F}(3.98)=6.47, p=0.01$ and explains $6.2 \%$ of the variance (corrected 
$R^{2}=0.052$ ). The results mean that individuals who learn more languages will be more likely to see positive effects of language learning in the area of purpose and motivation.

\section{Discussion}

The findings of this study reveal that the questionnaire statements on the basis of their meaning can be divided into four thematic groups: Intellect, Travelling and future, Positive emotions, and Purpose and motivation. The most consistent variable in both groups (Czech and Polish) were Positive emotions, which confirms our assumption that elderly people study a foreign language because it brings them happiness and personal satisfaction, which, consequently, positively affects their overall wellbeing (Pikhart \& Klimova, 2020). In addition, the findings show that the Polish respondents assessed the positive effects of FLL in all four thematic categories significantly higher than the Czech respondents. This might be associated with the fact that the number of the Poles with university education was higher than in the group of the Czech seniors. For instance, Belo et al. (2020) in their study report that seniors with high education and a more positive leisure attitude have a better psychological adjustment concerning wellbeing. Moreover, the Polish females evaluated the positive effects of FLL considerably higher than the Czech women. However, this discrepancy does not create any obstacle in concluding that in both groups of respondents the overall wellbeing levels obtained by FLL were very high, and this intervention by L2 acquisition can function as an efficient tool to improve QoL.

The results also reveal that the Czech seniors with secondary education compared to the Polish seniors with primary and vocational education assessed the increase in positive emotions caused by learning a foreign language higher than the Poles. As for other demographic factors (age, place of residence and number of languages) and their correlation to the positive effects of FLL, the findings do not show any significant differences in both experimental groups.

In addition, the results of the logistic regression analyses in the Czech group show that the more languages a senior learns, the more positive effects of FLL s/he perceives in the area of intellect. In the Polish group, this concerns only females. This is also evidenced by research studies on FLL and cognition and bilingualism, which imply that people who have a command of another foreign language or start learning it in older age may improve their cognitive skills (Antoniou, 2019; Bialystok, 2017; Bubbico et al., 2019; Wong et al., 2019).

Furthermore, motivation for older people to study a foreign language is their desire to travel, especially in the countries which were for a long time behind the iron curtain and people were not allowed to travel, i.e. both the Czech Republic and Poland. Moreover, those who can master more language are also more self-confident in encountering foreign cultures. Therefore, the results also indicate that individuals in both groups who learn more languages will be more likely to see positive effects of FLL in the area of travelling and future outlooks despite the age limitation of the participants of the study. The more language a Polish senior learns also indicates that s/he will more likely see positive effects of language learning in the area of purpose and motivation.

Naturally, there are several limitations to this study. First, the research sample is from two Central European countries, therefore, it is necessary to validate these findings on a larger scale. However, the research sample was representative enough and this limitation does not pose any threat to the reliability of the findings. Ideally, it would be beneficial to conduct similar research globally, or at least in several continents, to increase the statistical 
reliability. Second, the research was conducted in seniors, i.e. those who are older than 55 years. It would be interesting to focus only on a group of elderly people, e.g. older than 70 years, and observe how much L2 acquisition can help this cohort regarding their psychosocial well-being. However, it is extremely complicated to find a research sample large enough with these parameters, i.e. older than 70 and taking part in foreign language learning. But these parameters could also indicate future lines of research. Moreover, it seems important to determine what the cognitive mechanisms are responsible for this high level of subjective satisfaction and well-being.

The implications of our findings are both for the theory and practice. For the theory of psycholinguistics, these findings are crucial as there is no relevant or similar research into the topic we analyzed. Therefore, our findings have to be verified by on a large sale so as to provide psycholinguistic theory with relevant theoretical concepts regarding L2 acquisition in an older age. As we have already noted, the topic of L2 acquisition in an older age is still generally missing in psycholinguistic textbooks despite the fact that it is crucially beneficial and thus important not to be neglected or ignored. The implications for the practice result from the fact that L2 acquisition in an older age significantly improves the QoL and thus the well-being of the participant is enhanced, too. Therefore, FLL can be one of the intervention strategies, which can contribute to overall well-being among cognitively healthy seniors.

The research conducted clearly indicated that FLL or L2 acquisition in an older age can significantly improve the QoL in the participants, and that this improved level of wellbeing can function as a tool of psychosocial rehabilitation. The fact that the seniors take part in a cognitively stimulation environment and simultaneously they meet with their peers has a very positive effect on their increased sense of achievement, sense of life purpose and future prospects. FLL as an interventional method can function very well as a non-pharmacological tool, and if supplemented by physical activity, games, music, art, improved diet, etc., it can create a very prospective tool for psychosocial rehabilitation of seniors.

Acknowledgements The paper is supported by the project titled Excelence (2021) at the Faculty of Informatics and Management of the University of Hradec Kralove, Czech Republic.

Author Contributions Conceptualization, M.P. and B.K.; methodology, M.P. and B.K.; software, A.C.E. and S.D.; validation, M.P. and B.K.; formal analysis, A.C.E., S.D., M.P. and B.K.; investigation, M.P. and B.K.; resources, M.P. and B.K.; data curation, A.C.E., S.D., M.P. and B.K.; writing—original draft preparation, M.P. and B.K.; visualization, A.C.E., S.D., M.P. and B.K.; All authors have read and agreed to the published version of the manuscript.

Funding This research received no external funding.

\section{Declarations}

Conflicts of interest: The authors declare no conflict of interest.

Data availability Upon request from the corresponding author.

Open Access This article is licensed under a Creative Commons Attribution 4.0 International License, which permits use, sharing, adaptation, distribution and reproduction in any medium or format, as long as you give appropriate credit to the original author(s) and the source, provide a link to the Creative Commons licence, and indicate if changes were made. The images or other third party material in this article are included in the article's Creative Commons licence, unless indicated otherwise in a credit line to the material. If material is not included in the article's Creative Commons licence and your intended use is not 
permitted by statutory regulation or exceeds the permitted use, you will need to obtain permission directly from the copyright holder. To view a copy of this licence, visit http://creativecommons.org/licenses/by/4.0/.

\section{References}

Antoniou, M. (2019). The advantages of bilingualism debate. Annual Review of Linguistics., 5, 395-415.

Antoniou, M., \& Wright, S. M. (2017). Uncovering the mechanisms responsible for why language learning may promote healthy cognitive aging. Frontiers in Psychology, 8, 2217.

Belo, P., Navarro-Pardo, E., Pocinho, R., Carrana, P., \& Margarido, C. (2020). Relationship between mental health and the education level in elderly people: mediation of leisure attitude. Frontiers in Psychology, 11,573 .

Bialystok, E. (2017). The bilingual adaptation: How minds accommodate experience. Psychological Bulletin., 143(3), 233.

Bubbico, G., Chiacchiaretta, P., Parenti, M., di Marco, M., Panara, V., Sepede, G., Ferretti, A., \& Perrucci, M. G. (2019). Effects of second language learning on the plastic aging brain: Functional connectivity, cognitive decline, and reorganization. Frontiers in Neuroscience, 13, 423.

Cann, P. L. (2017). Arts and cultural activity: A vital part of the health and care system. Australasian Journal on Ageing, 36, 89-95.

Erickson, K. I., \& Kramer, A. F. (2009). Aerobic exercise effects on cognitive and neural plasticity in older adults. British Journal of Sports Medicine, 43, 22-24.

Gil-Lacruz, A., Gil-Lacruz, M., \& Saz-Gil, M. I. (2020). Socially Active Aging and Self-Reported Health: Building a Sustainable Solidarity Ecosystem. Sustainability, 12, 2665.

Klimova, B. (2018). Learning a foreign language: A review on recent findings about its effect on the enhancement of cognitive functions among healthy older individuals. Frontiers in Human Neuroscience, 12,305 .

Klimova, B., Maresova, P., \& Kuca, K. (2016). Non-pharmacological approaches to the prevention and treatment of Alzheimer's disease with respect to the rising treatment costs. Current Alzheimer Research, $13,1249-1258$.

Klimova, B., Novotny, M., \& Valis, M. (2020). The impact of nutrition and intestinal microbiome on elderly depression-a systematic review. Nutrients, 12, 710 .

Kormos, J., \& Csizer, K. (2008). Age-related differences in the motivation of learning English as a foreign language: attitudes, selves, and motivated learning behavior. Language Learning, 58(2), 327-355.

MacKean, R., \& Abbott-Chapman, J. (2011). Leisure activities as a source of informal learning for older people: The role of community-based organizations. Australas. J. Adult Learn., 51, 226-247.

Mathis, A., Rooks, R., \& Kruger, D. (2016). Improving the Neighborhood Environment for Urban Older Adults: Social Context and Self-Rated Health. International Journal of Environmental Research and Public Health, 13, 3.

Murman, D. L. (2015). The Impact of Age on Cognition. Seminars in Hearing, 36, 111-121. https://doi.org/ $10.1055 / \mathrm{s}-0035-1555115$

Phenninger, S. E., \& Polz, S. (2018). Foreign language learning in the third age: A pilot feasibility study on cognitive, socio-affective and linguistic drivers and benefits in relation to previous bilingualism of the learner. JESLA, 2, 1-13.

Pikhart, M., \& Klimova, B. (2020). Maintaining and Supporting Seniors' Wellbeing through Foreign Language Learning: Psycholinguistics of Second Language Acquisition in Older Age. International Journal of Environmental Research and Public Health, 17, 8038.

Salthouse, T. A. (2010). Selective review of cognitive aging. Journal of the International Neuropsychological Society, 16, 754-760. https://doi.org/10.1017/S1355617710000706

Serrat, R., \& Villar, F. (2019). Lifecourse transitions and participation in political organisations in older Spanish men and women. Ageing and Society, 40, 2174-2190. https://doi.org/10.1017/S0144686X1 9000618

Serrat, R., Villar, F., \& Celdrán, M. (2015). Factors associated with Spanish older people's membership in political organizations: The role of active aging activities. European Journal of Ageing, 12, 239-247.

Socci, M., Clarke, D., \& Principi, A. (2020). Active Aging: Social Entrepreneuring in Local Communities of Five European Countries. International Journal of Environmental Research and Public Health, 17, 2440.

Valis, M., Slaninova, G., Prazak, P., Poulova, P., Kacetl, J., \& Klimova, B. (2019). Impact of learning a foreign language on the enhancement of cognitive functions among healthy older population. Journal of Psycholinguistic Research, 48, 1311-1318. 
van den Elzen, N., Daman, V., Duijkers, M., Otte, K., Wijnhoven, E., Timmerman, H., \& Olde Rikkert, M. (2019). The Power of Music: Enhancing Muscle Strength in Older People. Healthcare, 7, 82.

Ware, C., Damnee, S., Djabelkhir, L., Cristancho, V., Wu, Y. H., Benovici, J., Pino, M., \& Rigaud, A.-S. (2017). Maintaining cognitive functioning in healthy seniors with a technology-based foreign language program: A pilot feasibility study. Front. Aging Neurosci., 9, 42.

Wilson, L., Harlow-Rosentraub, K., Manning, T., Simson, S., \& Steele, J. (2006). Civic engagement and lifelong learning. Generations, 30, 90-94.

Woll, B., Wei, L. (2019). Cognitive benefits of language learning: Broadening our perspectives. The British Academy.

Wong, P. C. M., Ou, J., Pang, C. W. Y., Zhang, L., Tse, C. S., Lam, L. C. W., \& Antoniou, M. (2019). Language training leads to global cognitive improvement in older adults: A preliminary study. Journal of Speech, Language, and Hearing Research, 62, 2411-2424.

Zhang, H., Dai, Y., \& Wang, Y. (2020). Motivation and second foreign language proficiency: the mediating role of foreign language enjoyment. Sustainability, 12, 1302.

Publisher's Note Springer Nature remains neutral with regard to jurisdictional claims in published maps and institutional affiliations.

\section{Authors and Affiliations}

\section{Marcel Pikhart ${ }^{1} \mathbb{D} \cdot$ Blanka Klimova $^{1} \cdot$ Anna Cierniak-Emerych $^{2} \cdot$ Szymon Dziuba $^{2}$}

Blanka Klimova

blanka.klimova@uhk.cz

Anna Cierniak-Emerych

anna.cierniak-emerych@ue.wroc.pl

Szymon Dziuba

szymon.dziuba@ue.wroc.pl

1 Department of Applied Linguistics, Faculty of Informatics and Management, University of Hradec Kralove, Hradec Kralove, Czech Republic

2 Faculty of Business and Management, Wroclaw University of Economics and Business, ul. Komandorska 118/120, 53-345 Wrocław, Poland 